\title{
A survey of knowledge, attitudes and practices regarding malaria and bed nets on Bubaque Island, Guinea-Bissau
}

\author{
Harry Hutchins ${ }^{1 *}$ (D), Grace Power ${ }^{1}$, Thomas Ant ${ }^{2}$, Eunice Teixeira da Silva ${ }^{1}$, Adriana Goncalves ${ }^{1}$, \\ Amabelia Rodrigues ${ }^{3}$, James Logan' ${ }^{1}$, David Mabey ${ }^{1}$ and Anna Last ${ }^{1}$
}

\begin{abstract}
Background: Malaria remains a significant public health problem in Guinea-Bissau, West Africa. Government control measures include bed net distribution campaigns, however, local knowledge, attitudes and practices towards bed nets and malaria are uncharacterized on the remote Bijagos Archipelago.

Methods: Knowledge, attitude and practice questionnaires were conducted with household heads, aiming to explore the understanding of malaria and factors influencing bed net uptake and usage. Nets were observed in situ to appraise net quality and behaviour. All 14 villages and one semi-urban neighbourhood on Bubaque Island were included. One in 5 households containing school-aged children were randomly selected.

Results: Of 100 participants, 94 were aware of malaria and 66 of those considered it a significant or severe problem, primarily because of its impact on health and income. Transmission, symptoms and risk factors were well known, however, $28.0 \%$ of participants felt under-informed. Some $80.0 \%$ reported contact with distribution campaigns, with inter-village variability. Campaign contact was associated with feeling well informed $(O R 3.44 ; P=0.024)$ and inversely with perceiving malaria a household $(O R 0.18 ; P=0.002)$ or regional problem $(O R 0.25 ; P=0.018)$. Every household contained nets; every identifiable example was a long-lasting insecticide-treated net (LLIN), however, 23.0\% of households contained at least one expired net. Replacements were in demand; $89.0 \%$ of households reported that all residents used nets, and average occupancy was 2.07 people per net; $65.2 \%$ stated that the repurposing of bed nets was common. Correctly using bed nets, defined by age, integrity and demonstration, was $35.0 \%$ and strongly associated with completing intermittent preventative treatment in pregnancy (RR 3.63; $\mathrm{P}=0.014$ ).
\end{abstract}

Conclusions: Knowledge of malaria is good in these communities. Bed nets are used widely and are valued for their role in preventing malaria. However, their use is frequently sub-optimal and offers a target for improving malaria control by adapting popular distribution campaigns to provide more education alongside fresh LLINs. The impact of this could be significant as LLINs represent the mainstay of malaria prevention in Guinea-Bissau; however, the persistence of malaria despite the high uptake of LLINs seen in this study suggests that novel supplementary approaches must also be considered.

Keywords: Guinea-bissau, Malaria, Bed net, Household, Knowledge, Attitudes, Practices

*Correspondence: harry.hutchins@lshtm.ac.uk

${ }^{1}$ London School of Hygiene and Tropical Medicine, Keppel Street, London WC1E 7HT, UK

Full list of author information is available at the end of the article

\section{Background}

Malaria remains a significant public health issue in Guinea-Bissau, West Africa [1]. Whilst it is well-characterized in the capital, Bissau [2], published data from elsewhere in the country are scarce. Rural communities 
are known to hold different beliefs about malaria and typically exhibit a higher disease burden [3-9]. The Bijagos Archipelago, lying off the Atlantic coast, consists of 88 islands and islets, approximately 20 of which are inhabited by small permanent and semi-permanent populations living predominantly in forest villages supported by subsistence agriculture. The islands' isolation presents significant challenges to healthcare provision, with no recent published epidemiological data to guide programmatic activities.

Government malaria control measures include enhanced case finding, intermittent preventive treatment in pregnancy (IPTp) and free triennial long-lasting insecticidal net (LLIN) distribution nationwide, most recently in May 2017. This latter intervention is at the core of national malaria control: it is employed across Guinea-Bissau, targets every citizen and significantly reduces malaria prevalence in other settings [10]. Distribution campaigns aim for universal coverage, for which there is greater evidence of efficacy than for previous targets of only pregnant women and children under five [11-15]. Campaigns are centrally organized and supplied, but implemented by voluntary local health workers within their communities. They aim to distribute one net per two people and provide basic information about malaria and bed nets, including their importance and correct use. Free nets are also supplied at antenatal clinic appointments. Optimizing net delivery has been shown to improve ownership and be important in malaria control [14]. Net ownership and usage behaviour are currently undescribed in these communities.

Understanding of malaria is variable across sub-Saharan African populations $[9,16,17]$ but no studies specifically examining Guinea-Bissau have been published since 1994. Other West African studies suggest good net uptake and that use persists, despite inconvenience, due to generally good understanding of their role in health $[12,13,15,18]$. Observations point to bed nets being highly valued and frequently repaired, retreated or replaced by users $[18,19]$. The impact of LLIN distribution has been evaluated in Bissau, suggesting a partial effect on an already falling prevalence $[1,2]$, and in rural areas of neighbouring Senegal, where it was associated with a dramatic reduction in malaria $[11-13,15,20]$.

Despite their importance to public health there is a paucity of information on the knowledge, attitudes and practices relating to malaria and bed nets in rural Guinea-Bissau, including the Bijagos Archipelago. The geographical and socio-cultural isolation of the islands make them an interesting study site, and given the central role LLIN play in Guinea-Bissau's malaria control programme, understanding their current status and use could have a profound impact on improving control of this important disease.

\section{Methods \\ Aims}

To explore population knowledge, attitudes and practices regarding malaria and bed nets on Bubaque Island, Guinea-Bissau and the factors that influence them; to collect data on bed net availability, quality and usage, and assess the impact of bed net distribution campaigns; to address knowledge gaps in the local implementation strategies of malaria control measures and, by supplying this information to officials, to ultimately guide and improve the delivery of malaria prevention programmes in line with the tenets of advocacy, communication and social mobilization.

\section{Design}

Population-based cluster-randomized cross-sectional survey.

\section{Setting}

This study was conducted in July 2018, early in the rainy season on Bubaque Island, Guinea-Bissau, one of the poorest and most politically unstable countries in the world [21]. Bubaque was selected so that this survey could be conducted alongside an ongoing malaria mapping survey. Bubaque is the most populous island (11,204, 52\% female) [22] in the Bijagos Archipelago. The average household size is 8 , with 4-6 children under 15 years old. Bubaque's population is divided between 14 rural villages, spread along the length of the island, and one larger semi-rural settlement (Praça) at Bubaque's northern end, which is sub-divided into 8 bairros (areas) of similar size. Praça's inhabitants have more personal wealth and better access to education, healthcare, better quality housing, and are serviced by weekly ferries to the mainland. Villages are preferentially situated within forests and practice subsistence agriculture. Traditional healing practices and animism are commonplace, especially in rural communities $[23,24]$.

\section{Participants}

All participants were household heads, identified by census. The unit of randomization was the household, defined as a 'fugon': those regularly eating from the same cooking pot over the preceding 30 days. Lists of all household heads were created prior to data collection by going door-to-door in each community. From this, a onein-five randomization was conducted within each village, to ensure all communities were included, as well as one random bairro in Praça, noting that bairros are significantly more populous. This proportion was selected to 
satisfy a sample size calculation for a concurrent malaria prevalence survey, which included a design effect of 2.0 to account for clustering. A census of selected households was performed to obtain demographic information about net users and to ensure every householder's behaviour was included in the survey. Households were excluded if they contained no school-aged children. Excluded households and those which were empty on data collection days were replaced with randomly selected reserve households.

\section{Procedure}

\section{Community sensitization}

Verbal consent was sought from community leaders before undertaking the study. Community health workers raised awareness and participants were asked to be at home on the day of data collection.

\section{Informed consent}

Information about the study's purpose and conduct was provided in Portuguese and Kriolu, the local dialect, during household-head listing and census taking. For participants who were not literate, the information was explained verbally in the presence of an impartial witness. After $24 \mathrm{~h}$, written informed consent was obtained by means of signature, or thumb print signature and witness signature where required. Contact details for study personnel fluent in Kriolu were provided to answer any questions. It was explicit that consent could be withdrawn by participants at any time.

\section{Sample collection and processing}

Questionnaires (Appendix 2) were translated by a Portuguese clinical researcher fluent in English and backtranslated by colleagues in the field for clarity. Two experienced Bissau-Guinean field assistants were trained to employ the questionnaire by $\mathrm{HH}$ and ETdS. They read Portuguese fluently and training was conducted in Kriolu, their first language. Training lasted a full day and was followed by piloting the survey on local field assistants under supervision. $\mathrm{HH}$ attended each village to supervise and assist during data collection. After the first village, the team reflected on the questionnaire and informal participant feedback, which was broadly positive: no changes were made. Discomfort at reporting other families' misuse of nets was raised by one participant, but welcomed by others.

Households were visited at pre-arranged times and surveys conducted in Kriolu. Survey data were collected using the Open Data Kit (ODK) secure data capture system supported by LSHTM (https://opendatakit.lshtm .ac.uk), onto password-protected android devices. If the household head was absent, the most senior adult present was interviewed instead, the household being excluded if no adults were present.

Questions were based on similar studies in African settings $[16,25]$ and were broadly divided into sociodemographic information, and knowledge, attitudes and practices regarding malaria and bed nets. Nets were observed in situ, prepared as if ready for use, to assess participants' behaviour and note the type of net via label photography.

Questions about malaria related to information sources, symptoms, transmission, risk and prevention. Net questions explored reasons for use, alternatives, number of nets, users, perceived safety, maintenance behaviour, obstacles to use, net misuse and campaign contact.

\section{Data management}

Consent forms and censuses, the only documents carrying names, were placed in locked storage; all other data were recorded anonymously, automatically encrypted and stored on a secure LSHTM server, meaning only authorized persons could view forms or data. Data underwent programmed and manual validity checks throughout collection. Study computers were password protected and kept in locked storage. An encrypted memory stick was used for physical data transfer. All documentation will be held for a minimum of 10 years. The final dataset has been archived.

\section{Statistics}

Analysis was conducted using EpiData Analysis software v2.2.3.187. Descriptive and frequency analyses were conducted for individual questions. Chi square tests and $\mathrm{t}$-tests were used to identify differences in quantitative variables between groups. Regression analysis was used to assess relationships between variables.

\section{Costs}

Excluding personal costs (e.g., housing and food) and international travel, and acknowledging that infrastructure was in place from prior studies, the total additional cost of staff and materials for this study was approximately GBP 400.

\section{Results}

The socio-demographic characteristics of the 100 household heads participating in the survey are shown in Table 1 . The mean age was 37.2 years (standard deviation $=14.4$ ), $57.0 \%$ were female and $78.0 \%$ had at least a primary education. The average household contained 6.8 people; $67.0 \%$ of households contained a child aged under 5 years, $16.0 \%$ contained a pregnant woman and $64.0 \%$ were in rural villages. One village had migrated to 
Table 1 Socio-demographic characteristics of participants $(n=100)$

\begin{tabular}{|c|c|}
\hline Variable & Frequency \\
\hline \multicolumn{2}{|l|}{ Gender } \\
\hline Male & 43 \\
\hline Female & 57 \\
\hline \multicolumn{2}{|l|}{ Age category } \\
\hline $18-29$ & 33 \\
\hline $30-49$ & 50 \\
\hline$\geq 50$ & 17 \\
\hline Mean (SD) & $37.18(14.40)$ \\
\hline \multicolumn{2}{|l|}{ Community } \\
\hline Rural & 64 \\
\hline Semi-urban & 36 \\
\hline \multicolumn{2}{|l|}{ Education } \\
\hline None & 22 \\
\hline Primary & 28 \\
\hline Secondary & 47 \\
\hline Tertiary & 3 \\
\hline \multicolumn{2}{|c|}{ Socio-economic ownership score } \\
\hline Low (1-3) & 50 \\
\hline Middle (4-6) & 36 \\
\hline High (7-19) & 14 \\
\hline Median (IQR) & $3.50(3.0-5.0)$ \\
\hline \multicolumn{2}{|l|}{ Household size } \\
\hline 1 to 4 & 23 \\
\hline 5 to 9 & 60 \\
\hline$\geq 10$ & 17 \\
\hline Mean (SD) & $6.80(2.93)$ \\
\hline \multicolumn{2}{|c|}{ Households with special groups } \\
\hline Under-5 $(n=96)$ & 67 \\
\hline Pregnant $(n=16)$ & 16 \\
\hline
\end{tabular}

another island for farming and contributed no participants, however all other villages were included, covering the length of the island.

Socio-economic status was approximated using a novel simplified score based on ownership of 10 locally relevant items, weighted by luxury, with a maximum value of 19 (Appendix 1): the median was 3.5 (interquartile range 3.0-5.0, range 1-13). Education was considered separately $[26,27]$.

\section{Malaria}

Awareness of malaria was expressed by $94.0 \%$ of participants. The most common sources of malaria information (Table 2) were radio $(86 / 94,91.5 \%)$, healthcare workers (76/94, 80.9\%), health centres $(73 / 94,77.7 \%)$, and net distribution campaigns (38/94, 40.4\%). Of all participants, $72.0 \%(72 / 100)$ believed they were sufficiently well informed about malaria and bed nets $(95 \%$ confidence
Table 2 Sources and desired sources of information regarding malaria and bed nets

\begin{tabular}{lll}
\hline & $\begin{array}{l}\text { Current } \\
\text { information source } \\
(\mathbf{\%})(\mathbf{n = 9 4 )}\end{array}$ & $\begin{array}{l}\text { Desired } \\
\text { information source } \\
(\mathbf{n = 1 0 0 )}\end{array}$ \\
\hline Radio & $86(91.5)$ & 85 \\
Healthcare workers & $76(80.9)$ & 83 \\
Health centres & $73(77.7)$ & 69 \\
Net distribution cam- & $38(40.4)$ & 42 \\
$\quad$ paigns & $17(18.1)$ & 14 \\
Family and friends & $11(11.7)$ & 11 \\
School & $10(10.6)$ & 39 \\
TV & $4(4.2)$ & 4 \\
Posters & $4(4.2)$ & 1 \\
Religious community & &
\end{tabular}

interval (CI): 63.0-81.0). Household heads over 30 years were more likely to feel well informed than those under 30 (RR 1.37, 95\% CI 1.14-6.89; $\mathrm{P}=0.022$ ) and reporting being well informed was associated with reporting full IPTp completion (RR 2.37, 95\% CI 1.00-5.60; P =0.024). Preferred sources for future education closely mirrored existing sources.

Every participant aware of malaria could name at least one symptom: fever $(92 / 94,97.9 \%)$ and pain $(83 / 91$, 91.2\%) being most frequent (Table 3). None described atypical malarial symptoms; 80/94 (85.1\%) identified

Table 3 Knowledge of malaria among participants reporting familiarity with the disease $(n=94)$

\begin{tabular}{lcl}
\hline Variable & Frequency (\%) & $\begin{array}{l}\mathbf{9 5 \%} \\
\text { confidence } \\
\text { intervals }\end{array}$ \\
\hline $\begin{array}{l}\text { Symptoms } \\
\text { Fever }\end{array}$ & $92(97.9)$ & $92.6-99.4$ \\
Pain & $83(91.2)(\mathrm{n}=91)$ & $83.6-95.5$ \\
Nausea and vomiting & $36(38.3)$ & $29.1-48.4$ \\
Anergia & $11(11.7)$ & $6.7-19.8$ \\
Confusion/convulsions & $6(6.4)$ & $3.0-13.2$ \\
Diarrhoea & $5(5.3)$ & $2.3-11.9$ \\
Transmission & & $76.5-90.9$ \\
Mosquito & $80(85.1)$ & $1.1-9.0$ \\
Other & $3(3.2)$ & $9.1-23.5$ \\
Don't know & $14(14.9)$ & \\
High-risk groups & & $79.0-92.2$ \\
Pregnant & $86(91.5)$ & $67.8-84.2$ \\
Infants & $77(81.9)$ & $64.6-81.6$ \\
Children & $73(77.7)$ & $47.2-66.3$ \\
Elderly & $57(60.6)$ & \\
\hline
\end{tabular}


mosquitoes as transmitting malaria; two participants additionally blamed person-person transmission and one blamed changing weather and contaminated drinking water. Radio education was associated with correctly describing transmission (OR 5.62, 95\% CI 1.25-25.33; $\mathrm{P}=0.033)$. Pregnant women $(86 / 94,91.5 \%)$ and infants $(77 / 94,81.9 \%)$ were most frequently identified as being high-risk groups.

Malaria was perceived to be a significant or severe household problem by $70.2 \%$ (66/94) of participants, and $71.3 \%(67 / 94)$ believed this was the case across the Bijagos; none believed that it was not a problem. There was strong evidence of an association between believing malaria to be a household problem and the perception of it being a problem more broadly in the Bijagos (RR 6.68, 95\% CI 2.69-16.58; $\mathrm{P}<0.001$ ). The primary reasons for concern were the risk of death $(42.0 \%)$, financial loss from not working and seeking healthcare (together $31.0 \%)$ and the risk of onward transmission (4.0\%). Those who denied that malaria was a problem pointed to low local prevalence. One participant believed malaria could only be caught once.

Awareness of IPTp was reported by $89.4 \%$ of participants. Among participating households, there had been 65 pregnancies in 48 households across the preceding two years. During 52/65 (80.0\%) of these pregnancies, women reported receiving the appropriate number of IPTp doses. Households in Bruce village, the largest rural community, were twice as likely to correctly implement IPTp (RR 2.00, 95\% CI 1.48-2.71; P = 0.029) as in other villages. Every household with a recent pregnancy believed that bed nets were safe for pregnant women, as did every household who reported learning about antenatal care during net distribution campaigns.

\section{Bed nets}

Almost all participants (99.0\%) reported taking measures to prevent insect bites: sleeping under bed nets (97.0\%), clearing standing water $(74.0 \%)$ and closing doors and windows at night (38.0\%) were most common (Table 4). All respondents reported using their nets to prevent malaria and all believed their nets were effective.

Every household owned at least one net, with a mean of 2.07 people using each net (SD 0.82). The number of nets within a household increased with socio-economic score $(0.2$ nets per integer; $95 \% \mathrm{CI} 0.06-0.35 ; \mathrm{P}=0.010)$ and with household size (0.32 nets per resident; $95 \% \mathrm{CI}$ $0.23-0.41 ; \mathrm{P}<0.001)$. Year-round use was reported by $90.0 \%$ of households, the remaining $10.0 \%$ during the wet season only; 15 individuals were reported to be sleeping without a net across 11 households in 8 villages; their characteristics did not differ significantly from the population. Households which believed nets were safe for
Table 4 Frequency of reported mosquito bite prevention measures $(n=100)$

\begin{tabular}{lll}
\hline Bite prevention method & Frequency & $\begin{array}{l}\mathbf{9 5 \%} \\
\text { confidence } \\
\text { intervals }\end{array}$ \\
\hline Bed nets & 97 & $91.5-99.0$ \\
Clearing standing water & 74 & $64.6-81.6$ \\
Closing doors/windows at night & 38 & $29.1-47.8$ \\
Burning dung & 22 & $15.0-31.1$ \\
Avoiding mosquito-infested areas & 20 & $13.3-28.9$ \\
Wearing long clothes & 18 & $11.7-26.7$ \\
Staying indoors & 5 & $2.2-11.2$ \\
Repellent smoke & 3 & $1.0-8.5$ \\
Repellent spray & 1 & $0.2-5.4$ \\
Window screens & 1 & $0.2-5.4$ \\
None & 1 & $0.2-5.4$ \\
\hline
\end{tabular}

Table 5 Frequency and determinants of incorrect bed net usage $(n=100)$

\begin{tabular}{|c|c|c|}
\hline & Frequency & $\begin{array}{l}95 \% \\
\text { confidence } \\
\text { intervals }\end{array}$ \\
\hline Correct use & 35.0 & $26.4-44.7$ \\
\hline \multicolumn{3}{|l|}{ Incorrect use } \\
\hline Beneath mattress & 42.0 & $32.8-51.8$ \\
\hline Holes & 41.0 & $32.5-51.3$ \\
\hline Net age & $22.8^{\mathrm{a}}$ & $14.9-33.2$ \\
\hline Above bed & 4.0 & $1.6-9.8$ \\
\hline Alteration & 3.0 & $1.0-8.5$ \\
\hline Storage & 2.0 & $0.6-7.0$ \\
\hline Size & 1.0 & $0.2-5.4$ \\
\hline
\end{tabular}

a $n=79$ due to damaged labels

children had a lower risk of residents sleeping without nets $(\mathrm{RR}=0.19,95 \% \mathrm{CI} 0.06-0.60 ; \mathrm{P}=0.059)$.

Correct net behaviour within a household was defined as all nets being in date, intact/repaired and correctly sized, stored and deployed on request; $35.0 \%$ of households met these criteria. The commonest deviations were not tucking under the mattress (42.0\%), disrepair (41.0\%) and excessive age (22.8\%) (Table 5). Correct behaviour was associated with full IPTp compliance (RR 3.63; 95\% CI $1.20-11.0 ; \mathrm{P}=0.014)$.

In total, $79.0 \%(79 / 100)$ of households contained nets with identifiable labels, all of which were LLINs, and $79.7 \%$ (63/79) of these households had nets from official distributions. The remainder came from unspecified sources. One was home-made. $77.2 \%$ (61/79) of homes were stocked entirely with in-date nets (less than three 
years old). Only $48.0 \%$ (48/100) of participants felt their households had enough nets.

Participants reported checking the integrity of their bed nets daily (85.0\%), weekly (12.0\%) and monthly (3.0\%). Replacement was preferred to retreatment: $53.0 \%$ desired a replacement net every 3 months, $20.0 \%$ every 6 months and $21.0 \%$ annually, whereas only $3.0 \%$ expressed interest in retreatment of any sort. Regarding sources of replacements, health centres $(88.0 \%)$ and distribution campaigns (77.0\%) were preferred to shops (10.0\%). Obstacles to obtaining new nets identified by participants included net cost $(63.0 \%)$, distance to point of distribution (15.0\%) and net availability (12.0\%).

Net washing was reported by $99.0 \%$ of respondents. Washing of nets was commonly described as being performed "when they were dirty", participants approximating this to a range of frequencies from daily (9.1\%) to less than three-monthly (5.0\%). Monthly (47.5\%) was most common. Some $78.8 \%$ (78/99) described drying their nets in the shade, in line with manufacturer's guidance (95\% CI 69.7-85.7\%); this was more likely in households deploying their nets correctly (RR 1.27 95\% CI 1.06-1.53; $\mathrm{P}=0.023$ ).

Almost all participants believed bed nets were safe for pregnant women (99.0\%) and children (96.0\%). Reasons given for believing them unsafe for children included overcrowding of nets, concerns about contact with the insecticide, and fears of bed net flammability.
Contact with the May 2017 bed net distribution campaign was reported by $80.0 \%$ of households (95\% CI 71.1$86.7 \%$ ). There was variation in campaign contact between communities, ranging from 33.3 to $100.0 \%$ (Fig. 1). Contact with the campaign was associated with feeling well informed about malaria and nets (OR 3.44, 95\% CI 1.245.97; $\mathrm{P}=0.024)$, and inversely associated with perceiving malaria as a severe problem at home (OR 0.18, 95\% CI $0.05-0.58 ; \mathrm{P}=0.002$ ) and on the Bijagos (OR 0.25, 95\% CI $0.08-0.83 ; \mathrm{P}=0.018)$. There was no statistically significant association between campaign contact and correct net usage (OR 2.53, 95\% CI 0.77-8.27; $\mathrm{P}=0.116$ ).

Some $6.0 \%$ of participants acknowledged using nets for other purposes including fishing, protecting crops, filtering juice and drying foodstuffs; $24.0 \%$ mentioned observing other community members using nets for these activities: $33.3 \%(8 / 24)$ stated it was uncommon, $54.2 \%(13 / 24)$ common and $8.3 \%(2 / 24)$ very common. Researchers frequently observed nets employed as fences, outhouse walls, football goals and anti-erosion barriers; nets from the most recent distribution campaign were identified being repurposed, despite community claims that only old nets were repurposed.

\section{Discussion}

Awareness and knowledge of malaria was high in this study population. Individuals displayed knowledge encompassing transmission, prevention and risk groups,

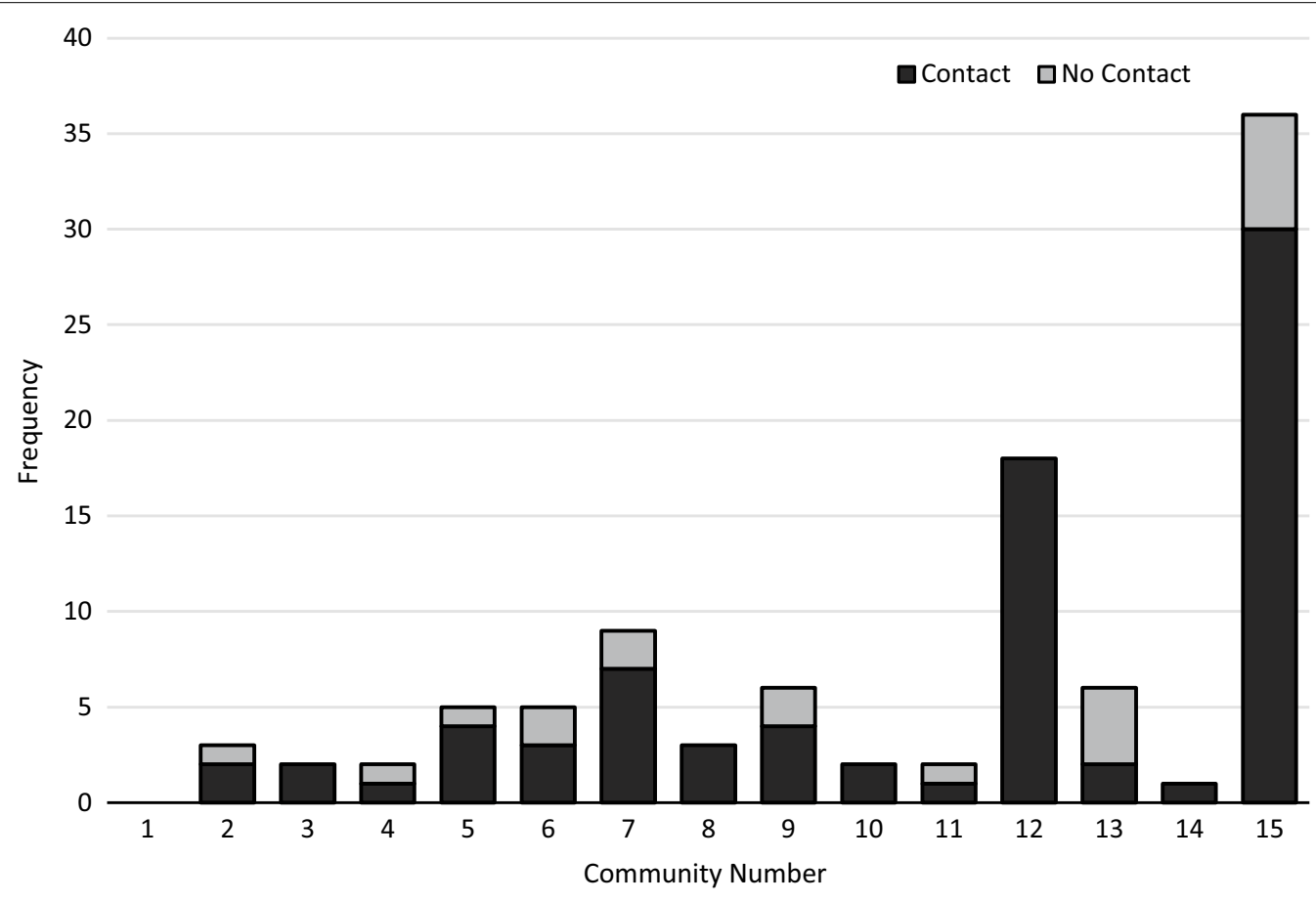

Fig. 1 Frequency of reported contact with bed net distribution campaigns across communities 
suggesting a broad comprehension of malaria and the success of education efforts; $72.0 \%$ of participants felt well informed but there remains room for improvement, especially as younger participants felt less informed. This may be related to knowledge, experience or awareness of their limitations.

Although infrequently listed as a source of information, contact with distribution campaigns was associated with feeling well informed. This supports their future use as education platforms. Their potential could be significant given campaign household coverage of $80.0 \%$ and participants' stated preference for receiving information from healthcare sources. Given the limited resources of the local health system, distribution campaigns constitute an important additional contact opportunity [28]. Radio is highlighted as a popular and accessible alternative whilst school programmes, effective elsewhere [29-32], could increase the small numbers currently reporting learning about malaria in school here.

Population perceptions of malaria as a severe problem suggest an appetite for education and preventive interventions. Human and financial loss, the primary drivers of this perception, could be targeted during education to reinforce its importance. The complexity or breadth of information provided could also be expanded given participants' strong baseline understanding, perhaps challenging specific misconceptions around net safety or seasonal use.

Eighty per cent of pregnancies correctly received IPTp; as IPTp adherence was associated with correct net use and belief in their safety, improving this figure may yield significant benefits. However, the potential role of variable education between households as a confounder for these effects requires further evaluation. It was striking that Bruce village had twice the average adherence of other villages. Awareness of the programme and local promotion are both known to improve uptake [33, 34], suggesting positive work by community health workers; alternatively Bruce's size and association with a small hotel may improve its access to transport for healthcare. Applying these to other communities may improve uptake.

LLIN ownership was universal and very few residents were reported sleeping without them, which is exceptional for the region [35-38]. All participants believed nets were effective at preventing malaria and $>95.0 \%$ believed they were safe for pregnant women and children. Non-users were so few that characteristics for targeted interventions could not be identified. However, only $77.2 \%$ of label-identifiable nets were in-date, meaning the true figure is likely lower, and correct use stood at only $35.0 \%$, with intra-household variability; 2.07 users per net is also slightly in excess of targets and occupants are more likely to sleep against the net, reducing efficacy [39]. The incorrect use and damage, including frequent washing, of bed nets reduces their effectiveness, contributing to the ongoing circulation of malaria in this community [40]. Only $48.0 \%$ of households felt they had sufficient nets for their needs and $94.0 \%$ desired more frequent replacements. While education may raise awareness, improved access to quality nets is ultimately needed.

As participants are reluctant and often unable to purchase nets, replacement must be government-driven. WHO/Global Malaria Programme recommend comprehensively resourced triennial distribution campaigns with trained and motivated staff as the only proven cost-effective method to achieve this, with continuous supplementary distribution from antenatal clinics and immunisation programmes [41]. Top-up campaigns are not recommended. An ideal campaign would reach every household, distribute one net per 1.8 people and provide information aimed at eliminating misconceptions and increasing correct net use to $100 \%$ year-round. A thorough census is key to a successful delivery programme [14].

Given malaria's continued presence despite the notably high bed net coverage, it can be concluded that distribution campaigns, the cornerstone of malaria control in Guinea-Bissau, are insufficient to eliminate malaria. New techniques will be required to supplement these if elimination is to be achieved. Further research is required to identify locally appropriate methods, perhaps improving IPTp access or vector control. A summary of recommendations is given in Table 6.

Bed nets were clearly valued; participants described conscientious maintenance behaviour, nets were used long past expiration and frequently showed signs of repair, although retreatment was unpopular. Teaching and providing repair supplies were used effectively in Senegal $[18,19]$ and could feasibly be applied here if net distribution proves inadequate. Improving awareness of, and access to, antenatal clinic net distribution may improve household access to nets, IPTp and antenatal care. Opportunistic malaria advice can also be given, as in Nigeria [42], satisfying local preference for replacing nets and receiving malaria information via healthcare sources. Providing free nets is especially important to Bubaque's poorer families which had fewer nets per person, and evidence from elsewhere in Africa suggests a complex bidirectional relationship between malaria and poverty $[27,43,44]$.

Whilst net repurposing was rarely reported by participants, it was a visible problem. Observational or qualitative studies could quantify this and illuminate underlying reasons. Behaviour change and convincing populations of their greater value as healthcare tools are required, 
Table 6 Recommendations to improve malaria control measures on Bubaque island

\begin{tabular}{|c|c|}
\hline Distribution campaign & Governmental \\
\hline $\begin{array}{l}\text { Ensure a thorough census prior to starting } \\
\text { Ensure every community has adequate access to the campaign } \\
\text { Reach the missing } 20 \% \text { of households through improved sensitisation, } \\
\text { social contacts or door-knocking } \\
\text { Ensure sufficient supplies of nets } \\
\text { Provide } 1 \text { net per } 1.8 \text { people } \\
\text { Attach a dedicated "health educator," (nurse or trained community health } \\
\text { worker) to provide information on malaria, bed nets and IPTp. This could } \\
\text { be expanded to other topics } \\
\text { Provide pictorial/written instructions for correct net use at distribution e.g. } \\
\text { tucking the net, occupancy, age of expiry } \\
\text { Consider providing net repair kits (and instructions) with each net } \\
\text { Improve the longevity of net labels, for identification of net age. This may } \\
\text { require collaboration with manufacturers }\end{array}$ & $\begin{array}{l}\text { Provide regular education programmes in schools, using teachers or } \\
\text { healthcare workers } \\
\text { Utilise local radio during and between campaigns. Sensitise communities } \\
\text { and provide education on malaria prevention/identification and correct } \\
\text { net use/care } \\
\text { Education should highlight the potential human and financial cost of } \\
\text { malaria, and misconceptions about net use and safety } \\
\text { Ensure antenatal and immunisation programmes advertise the availability } \\
\text { of free bed nets and are well-stocked to do so. Evaluate their distribution } \\
\text { Consider a net exchange programme for broken/expired nets at the } \\
\text { hospital } \\
\text { Increase funding for, or access to, transport to hospital } \\
\text { Extend these surveys to other islands for comparison } \\
\text { Take measures to reduce poverty and improve access to items for which } \\
\text { bed nets might be substituted e.g. fishing nets }\end{array}$ \\
\hline
\end{tabular}

especially as malaria's falling prevalence reduces its visibility [1]. Health-seeking, malaria prevention and netreplacement behaviour are heavily influenced by financial impact in this low-resource population: reducing healthcare costs will be an important mechanism in reducing malaria.

There are several limitations to this work. Social acceptability bias is likely given that researchers were healthcare workers, but was mitigated by observing net practices and training assistants in interview technique (to also reduce interviewer bias). Collecting data during the rainy season, when malaria is more visible, may produce biased results. At this time, three villages migrate to another island for farming, therefore contributing fewer/no participants; a comparative dry season survey would limit both issues. Rural and smaller communities were over-represented and differences with Praça may be hidden by type 2 error, but including every village was deemed desirable as behaviour might reasonably cluster within communities and this was accounted for by using a design effect in the sample size calculation. Increasing the sample by including remaining bairros or other islands may reduce this error. Due to being a crosssectional study, the unemployed, farmers or those lacking the resources to travel may be over-represented relative to economic migrant workers, however attitudes and practices transpired to be reasonably homogenous across socio-economic groups. Improved telecommunications may capture more household heads. Lastly, given the islands' isolated and distinct nature, generalisability may be limited to the Bijagos: work on other islands and the mainland may be required to assess this due to a paucity of data, but results seem markedly different to surveys in nearby Guinea-Conakry and Sierra Leone [38, 45].

\section{Dissemination}

The ultimate aim of this work was to improve the delivery of malaria control measures in these communities. To this end, an executive summary will be produced in Portuguese and English, and forwarded to the regional health office, the Bissau-Guinean public health institute and the malaria control office at the Ministry of Health, alongside this paper. Meetings will be held in-person with these stakeholders at the earliest opportunity, and results presented at the Bandim Health Project research meeting in Bissau. Results have been discussed at a meeting with field assistants and community healthcare workers, who were asked to share the outcomes with their communities. Consideration will be given to the feasibility of a local radio broadcast by $\mathrm{HH}$ and ETdS to discuss the results and improve awareness.

\section{Conclusion}

This is the first study to examine knowledge, attitudes and practices towards malaria and bed nets in GuineaBissau. Knowledge of malaria is good in these communities and it is an important local concern due to its health and economic impact. LLINs are widely used and highly valued, however their quality and use could be improved. Properly resourced bed net distribution campaigns might provide a solution through both net provision and education, making them an exciting potential component of future malaria control programmes, acknowledging that with such high existing coverage and the difficulty of effecting behaviour change, additional measures 
will be required to eliminate malaria from the Bijagos Archipelago.

\begin{abstract}
Abbreviations
95\% Cl: 95\% confidence interval; IPTp: Intermittent preventive treatment in pregnancy; LLIN: Long-lasting insecticide-treated net; ODK: Open data kit; OR: Odds ratio; RR: Relative risk.
\end{abstract}

\section{Acknowledgements}

We acknowledge the work of our field assistants, especially Marcelino da Silva and Julio Caetano Gomes, and community health workers in facilitating data collection. We acknowledge Open Data Kit (ODK) for providing the software used to collect the data for this project, and the assistance of Chrissy Roberts, LSHTM, in troubleshooting. We acknowledge the Bandim Project in Bissau for providing printing, telecommunications, medication and accommodation.

\section{Authors' contributions}

$\mathrm{HH}$ planned and wrote the research protocol, conducted data collection by training and supervising local assistants, performed all data analysis and wrote the manuscript. GP and TA provided significant assistance constructing the protocol and reviewing the manuscript. TA also provided data analysis advice. EC provided support and translation services in the field, and assisted in training and supervision. AG provided logistic support and preparatory training. AR provided administrative support at a senior level and advice on conducting research in Guinea-Bissau. JL and DM provided senior input on hypothesis generation and protocol creation. AL supervised the project, providing advice on logistics, planning and data analysis, as well as reviewing the manuscript.

All authors read and approved the final manuscript.

\section{Funding}

This study was supported in part by a LSHTM trust fund scholarship awarded to $\mathrm{HH}$, and by an MRC Global Challenges Research Fund grant (MR/P023843/1) awarded to DM. Funders had no role in the collection, analysis or interpretation of data or in the preparation of this manuscript.

\section{Availability of data and materials}

The datasets used during this study are available from the corresponding author on reasonable request. They are also available in the LSHTM Data Compass repository, https://datacompass.Ishtm.ac.uk/cgi/users/home?scree n=EPrint\%3A\%3AView\&eprintid $=1849$

\section{Ethics approval and consent to participate}

Ethical approval for this study was obtained from LSHTM Ethics Committee, the Comité Nacional de Eticas na Saúde of Guinea-Bissau and The MRC The Gambia Scientific Research Committee. This research was conducted in accordance with the Declaration of Helsinki. Consent and data management procedures were comprehensive and have been outlined in the text. Results have been disseminated to local communities through resident field assistants. Please note that there was no remuneration or other compensation offered for participation.

\section{Consent for publication}

Not applicable.

\section{Competing interests}

The authors declare that they have no competing interests.

\section{Author details}

${ }^{1}$ London School of Hygiene and Tropical Medicine, Keppel Street, London WC1E 7HT, UK. ${ }^{2}$ University of Glasgow, University Avenue, Glasgow G12 8QQ, UK. ${ }^{3}$ Projecto de Saúde Bandim, Apartado 8611004 , Bissau Codex, Guinea-Bissau.

\section{Appendix 1: Novel scoring system for the approximation of socio-economic status}

\begin{tabular}{ll}
\hline Item & Score \\
\hline Animals & 1 \\
Mobile phone & 1 \\
Radio & 1 \\
Farmland & 1 \\
TV & 2 \\
Bicycle & 2 \\
Electricity & 2 \\
Moped & 3 \\
Canoe & 3 \\
Bank account & 3 \\
\hline
\end{tabular}

Appendix 2: Questionnaire used for data collection

(original format: ODK electronic questionnaire)

1. Staff initials

2. Village name

3. Village/household/participant ID number (with repeat)

4. Age in years (number)

5. Gender (select one)
a. Male
b. Female

6. Household head education level (select one)
a. None
b. Primary
c. Secondary
d. Higher

7. How many people in your household are under 5 ? (number)

8. How many people in your household are aged 5-14? (number)

9. How many people in your household are aged 15-34? (number)

10. How many people in your household are aged 35-54? (number)

11. How many people in your household are over 54? (number)

12. How many people in your household are pregnant? (number)

13. Does anyone in your household own any of these items? (select multiple) 

a. Electricity
b. Radio
c. Mobile telephone
d. TV
e. Bicycle
f. Moped
g. Canoe
h. Motorboat
i. Car
j. Animals
k. Agricultural land
1. Bank account

14. Have you heard of malaria? (select one)
a. Yes
b. No

15. Where did you learn about malaria? (select multiple)
a. Friends and family
b. School
c. Healthcare workers
d. Healthcare facility
e. Governmental education and bed net distribu- tion campaigns
f. Radio
g. TV
h. Religious buildings
i. Posters/pamphlets
j. Other (specify)

16. What are the symptoms of malaria? (select multiple)
a. Don't know
b. Fever/sweating
c. Nausea and vomiting
d. Diarrhoea
e. Confusion
f. Loss of energy/fatigue
g. Pain
h. Other (specify)

17. How is malaria transmitted? (select multiple)
a. Don't know
b. Contaminated air
c. Drinking unsafe water
d. Eating unsafe food
e. Mosquito bites
f. Others insects or vectors
g. Contact with animals
h. Contact with someone who has malaria
i. Wet weather or changing weather
j. Spirits, energy or magic
k. Other (specify)

18. Which people need special protection from malaria? (select multiple)
a. Don't know
b. Children under 5
c. All children
d. Adults
e. Pregnant women
f. Certain professions (specify)
g. Other (specify)

19. Why do they need protection? (free text)

20. Are you aware that all women should receive malaria treatment during pregnancy, even if they are healthy?
a. Yes
b. No

21. How many pregnancies have there been in this household during the last 2 years? (number)

22. For each pregnancy:

a. Did the woman receive malaria medication?
i. Yes
ii. No

b. How many times during the pregnancy? (number)

i. If $>3$, why more than three?

23. How much of a problem is malaria in your household? (select one)
a. It is not a problem
b. It is an insignificant problem
c. It is a somewhat significant problem
d. It is a significant problem

24. Why? (free text)

25. How much of a problem is malaria on the Bijagos? (select one)

a. It is not a problem

b. It is an insignificant problem 
c. It is a somewhat significant problem

d. It is a significant problem

26. Why? (free text)

27. What time do you normally go to bed?

28. What time do you normally wake up?

29. How do you personally protect yourself from mosquito bites? (select multiple)
a. I do not protect myself
b. Bed nets
c. Insecticide cream or spray
d. Insecticide coils or smoke
e. Staying indoors at night
f. Screens on doors and windows
g. Close doors and windows
h. Indoor residual spraying
i. Wearing long clothes
j. Clearing stagnant water
k. Avoiding places with many mosquitoes
1. Burning dung or leaves
$\mathrm{m}$. Traditional medicine or practices
n. Other (specify)
o. Don't know

30. Have you had any contact with the bed net distribution campaign? (select one)
a. Yes
b. No

31. What did they inform you about? (select multiple)
a. Why to use bed nets
b. How to use bed nets
c. Insects
d. Malaria disease
e. Child health
f. Antenatal health
g. Other health issues
h. Other (specify)
i. Don't know

32. How many bed nets do you have in your home? (number)

33. (If none) Why do you not use bed nets?
a. I want to use them but we have none
b. They are unsafe
c. They are uncomfortable
d. They smell bad
e. I have a bad reaction to them/they make me ill
f. They are difficult to use
g. They take too much time to set up
h. They are not effective
i. They are too valuable to use regularly
j. Other (specify)
k. Don't know

34. Do you think bed nets are safe for children? (select one)
a. Yes
b. No

35. Why?

36. Do you think bed nets are safe for pregnant women? (select one)
a. Yes
b. No

37. Why?

38. (If they own any nets) For each bed net in the home:

a. What type of bed net is it? (select one)

i. LLIN

ii. ITN
iii. Untreated

b. Is the bed net being used? (select one)

i. Yes

ii. No

1. Why not? (select one)
a. It is unsafe
b. It is uncomfortable
c. It smells bad
d. I have a bad reaction to them/they make me ill
e. They are difficult to use
f. They take too much time to set up
g. They are not effective
h. They are too valuable to use regularly
i. Our old net works so we have not replaced it
j. We use the net for something else
k. Other (specify)
l. Don't know

c. How old is the bed net? (select one) 
ii. $3-6$ months

iii. 6-12 months

iv. 1-2 years

v. 2-3 years

vi. $>3$ years

vii. Don't know

d. Where did you get the be net?

\section{i. Health centre}

ii. Healthcare workers

iii. Government distribution campaign in this community

iv. Government distribution campaign in another community

v. Bought in a shop

vi. Found it

vii. Given by friends/relatives

viii. Other (specify)

ix. Don't know

e. Who slept under the net last night?

i. List age and gender of each

39. Is there anyone in the household who did not sleep under a net last night? (select one)

a. Yes (specify age, gender, pregnant)

b. No

40. Why do you use a bed net? (select multiple)
a. To prevent malaria
b. To prevent other diseases (specify)
c. To prevent nuisance biting
d. To keep animals out
e. Other (specify)
f. Don't know

41. Do you think your bed net is effective? (select one)
a. Yes
b. No

42. What time of year do you use your bed net? (select one)
a. All year
b. Rains only
c. Dry season only
d. Other (specify)
e. Don't know

43. Do you wash your bed nets? (select one)

a. Yes

i. How often? (select one)

1. Daily

2. Weekly

3. Monthly

4. 3 monthly

5. 6 monthly

6. Annually

7. Other (specify)

8. Don't know

ii. Where do you dry your nets? (select one)
1. Indoors
2. Outdoors (sun)
3. Outdoors (shade)
4. Don't know

b. No

44. How often do you check the integrity of your bed net?
a. Never
b. Daily
c. Weekly
d. Monthly
e. 3 monthly
f. 6 monthly
g. Annually
h. Other (specify)
i. Don't know

45. Would you retreat your bed net with insecticide? (select one)
a. 3 monthly
b. 6 monthly
c. Annually
d. Every 2 years
e. Every 3 years
f. Other (specify)
g. Don't know
h. No

46. How often should you replace your bed net?

a. 3 monthly 

b. 6 monthly
c. Annually
d. Every 2 years
e. Every 3 years
f. Other (specify)
g. Don't know

47. Where would you get replacement bed nets?
a. Health centres
b. Government distribution campaigns
c. Buy in a shop
d. Borrow from friends/family
e. Other (specify)
f. Don't know

48. Do you feel you have enough bed nets? (select one)
a. Yes
b. No

49. What are the main difficulties you face in obtaining a new bed net?
a. Cost
b. Distance
c. Availability
d. Waiting for the next distribution campaign
e. Other (specify)
f. Don't know

50. Do you feel you are given enough information about bed nets? (select one)
a. Yes
b. No

51. How would you like to receive healthcare information? (select multiple)
a. I do not want to receive information
b. Friends and family
c. School
d. Healthcare workers
e. Healthcare centres
f. Government education campaigns
g. Radio
h. TV
i. Religious buildings
j. Posters/pamphlets
k. Other (specify)
1. Don't know

52. Do you use your bed nets for any other purposes? (select one)
a. Yes (specify)
b. No

53. Do you know any purposes that other people use their bed nets for? (select one)
a. Yes (specify)
b. No

54. How common is this? (select one)
a. Very common
b. Common
c. Uncommon
d. Rare
e. Don't know

55. Observe every bed net in the household in situ. Ask the household to arrange them as though ready for use. For each bed net:

a. Where is the bed net stored when not in use?

i. Over the bed at all times

ii. Indoors, covered

iii. Indoors, uncovered

iv. Outdoors, covered

v. Outdoors, uncovered
vi. Other (specify)

b. Is the bed net hung over the bed? (select one)
i. Yes
ii. No

c. Is the bed net tucked under the mattress? (select one)
i. Yes
ii. No

d. Is the bed net an appropriate size? (select one)
i. Yes
ii. No

e. Are there any holes large enough to admit your thumb in the bed net? (select one) 

i. Yes
ii. No

\section{f. Are there any signs of alteration to the bed net? (select one)}

ii. Yes, repair

$$
\text { i. Yes, damage }
$$

iii. $\mathrm{No}$

\section{Is there an open water source near the building? (select one)}
a. Yes (specify)
b. No

Received: 10 April 2020 Accepted: 29 October 2020

Published online: 17 November 2020

\section{References}

1. Ursing J, Rombo L, Rodrigues A, Aaby P, Kofoed PE. Malaria transmission in Bissau, Guinea-Bissau between 1995 and 2012: malaria resurgence did not negatively affect mortality. PLoS ONE. 2014;9:e0101167.

2. Rodrigues A, Schellenberg JA, Kofoed PE, Aaby P, Greenwood B. Changing pattern of malaria in Bissau. Guinea Bissau Trop Med Int Health. 2008;13:410-7.

3. Appawu M, Owusu-Agyei S, Dadzie S, Asoala V, Anto F, Koram K, et al. Malaria transmission dynamics at a site in northern Ghana proposed for testing malaria vaccines. Trop Med Int Health. 2004;9:164-70.

4. Lindsay SW, Campbell H, Adiamah JH, Greenwood AM, Bangali JE, Greenwood BM. Malaria in a peri-urban area of The Gambia. Ann Trop Med Parasitol. 1990;84:553-62.

5. Robert V, Macintyre K, Keating J, Trape JF, Duchemin JB, Warren M, et al. Malaria transmission in urban sub-Saharan Africa. Am J Trop Med Hyg. 2003;68:169-76.

6. Keiser J, Utzinger J, Caldas De Castro M, Smith TA, Tanner M, Singer BH. Urbanization in sub-Saharan Africa and implication for malaria control. Am J Trop Med Hyg. 2004;71:118-27.

7. Hay SI, Guerra CA, Tatem AJ, Atkinson PM, Snow RW. Urbanization, malaria transmission and disease burden in Africa. Nat Rev Microbiol. 2005:3:81-90

8. Iqbal SA, Botchway F, Badu K, Wilson NO, Dei-Adomakoh Y, DickinsonCopeland CM, et al. Hematological differences among malaria patients in rural and Urban Ghana. J Trop Pediatr. 2016;62:477-86.

9. Aikins MK, Pickering H, Greenwood BM. Attitudes to malaria, traditional practices and bednets (mosquito nets) as vector control measures: a comparative study in five west African countries. J Trop Med Hyg. 1994;97:81-6.

10. Yang GG, Kim D, Pham A, Paul CJ. A meta-regression analysis of the effectiveness of mosquito nets for malaria control: the value of long-lasting insecticide nets. Int J Environ Res Public Health. 2018;15:546.

11. Wotodjo AN, Richard V, Boyer S, Doucoure S, Diagne N, Toure-Balde A et al. The implication of long-lasting insecticide-treated net use in the resurgence of malaria morbidity in a Senegal malaria endemic village in 2010-2011. Parasit Vectors. 2015;8:267.

12. Wotodjo AN, Doucoure S, Gaudart J, Diagne N, Sarr FD, Faye N, et al. Malaria in Dielmo, a Senegal village: Is its elimination possible after seven years of implementation of long-lasting insecticidetreated nets? PLOS ONE. 2017:12:e0179528.
13. Thwing JI, Perry RT, Townes DA, Diouf MB, Ndiaye S, Thior M. Success of Senegal's first nationwide distribution of long-lasting insecticide-treated nets to children under five - Contribution toward universal coverage. Malar J. 2011;10:86.

14. Zegers De Beyl C, Koenker H, Acosta A, Onyefunafoa EO, Adegbe E, McCartney A, et al. Multi-country comparison of delivery strategies for mass campaigns to achieve universal coverage with insecticide-treated nets: what works best? Malar J. 2016;15:58.

15. Trape JF, Tall A, Sokhna C, Ly AB, Diagne N, Ndiath O, et al. The rise and fall of malaria in a west African rural community, Dielmo, Senegal, from 1990 to 2012: a 22 year longitudinal study. Lancet Infect Dis. 2014;14:476-88.

16. Taremwa IM, Ashaba S, Adrama HO, Ayebazibwe C, Omoding D, Kemeza I, et al. Knowledge, attitude and behaviour towards the use of insecticide treated mosquito nets among pregnant women and children in rural Southwestern Uganda. BMC Pub Health. 2017;17:794.

17. Nganda RY, Drakeley C, Reyburn H, Marchant T. Knowledge of malaria influences the use of insecticide treated nets but not intermittent presumptive treatment by pregnant women in Tanzania. Malar J. 2004;3:42.

18. Berthe S, Loll D, Faye SL, Wone I, Koenker H, Arnold B, et al. "When I sleep under the net, nothing bothers me; I sleep well and I'm happy": Senegal's culture of net use and how inconveniences to net use do not translate to net abandonment. Malar J. 2014;13(1):357.

19. Loll DK, Berthe S, Faye SL, Wone I, Arnold B, Koenker H, et al. "You need to take care of it like you take care of your soul": perceptions and behaviours related to mosquito net damage, care, and repair in Senegal. Malar J. 2014;13:322.

20. Diop F, Richard V, Diouf B, Sokhna C, Diagne N, Trape JF, et al. Dramatic declines in seropositivity as determined with crude extracts of Plasmodium falciparum schizonts between 2000 and 2010 in Dielmo and Ndiop. Senegal Malar J. 2014;13:83.

21. World Bank. Guinea-Bissau Overview. The World Bank. 2018. Available from: https://www.worldbank.org/en/country/guineabissau/overviewAccessed 19 Aug 2018

22. República da Guiné-Bissau, Ministério da economia e finanças. População por região, sector, localidade e por sexo - RGPH2009. Instituto Nacional de Estatística. 2009. p. 56-9. https://dataspace.princeton.edu/bitst ream/88435/dsp01w6634600z/11/DSPACEGuineaBissaucensus2008re giaoRGPH2009.pdf. Accessed 25 Feb 2018

23. Thompson K, Hutchins H, Baio A, Cassama E, Nabicassa M, Bailey R, et al. Health Beliefs and Perceptions of Trachoma in Communities on the Bijagos Archipelago of Guinea Bissau. Ophthalmic Epidemiol. 2015;22:190-9.

24. Cross HC. The importance of small-scale fishing to rural coastal livelihoods: a comparative case-study in the Bijagós Archipelago Guinea Bissau. University College London; 2014. https://discovery.ucl.ac.uk/14174 89/2/Helen Cross Thesis edited version.pdf. Accessed 7 Oct 2019

25. Baume CA, Reithinger R, Woldehanna S. Factors associated with use and non-use of mosquito nets owned in Oromia and Amhara Regional States. Ethiopia Malar J. 2009;8:264.

26. Vyas S, Kumaranayake L. Constructing socio-economic status indices: how to use principal components analysis. Health Policy Plan. 2006;21:459-68.

27. Krefis AC, Schwarz NG, Nkrumah B, Acquah S, Loag W, Sarpong N, et al. Principal component analysis of socioeconomic factors and their association with malaria in children from the Ashanti Region. Ghana Malar J. 2010;9:201.

28. Fronteira I, Sidat M, Fresta M, do Rosário Sambo M, Belo C, Kahuli C, et al. The rise of medical training in Portuguese speaking African countries. Hum Resour Health. 2014;12:63.

29. Ayi I, Nonaka D, Adjovu JK, Hanafusa S, Jimba M, Bosompem KM, et al. School-based participatory health education for malaria control in Ghana: engaging children as health messengers. Malar J. 2010;9:98.

30. Okabayashi $\mathrm{H}$, Thongthien $\mathrm{P}$, Singhasvanon P, Waikagul J, Looareesuwan $\mathrm{S}$, Jimba M, et al. Keys to success for a school-based malaria control program in primary schools in Thailand. Parasitol Int. 2006:55:121-6.

31. Onyango-Ouma W, Aagaard-Hansen J, Jensen BB. The potential of schoolchildren as health change agents in rural western Kenya. Soc Sci Med. 2005;61:1711-22.

32. Nonaka D, Kobayashi J, Jimba M, Vilaysouk B, Tsukamoto K, Kano S, et al. Malaria education from school to community in Oudomxay province. Lao PDR Parasitol Int. 2008;57:76-82. 
33. Gies S, Coulibaly SO, Ouattara FT, Ky C, Brabin BJ, D'Alessandro U. A community effectiveness trial of strategies promoting intermittent preventive treatment with sulphadoxine-pyrimethamine in pregnant women in rural Burkina Faso. Malar J. 2008;7:180.

34. Amoran OE, Ariba AA, lyaniwura CA. Determinants of intermittent preventive treatment of malaria during pregnancy (IPTp) utilization in a rural town in Western Nigeria. Reprod Health. 2012;9:12.

35. Rodrigues A, Schellenberg JA, Roth A, Benn CS, Aaby P, Greenwood B. Revaccination with Bacillus Calmette-Guerin (BCG) vaccine does not reduce morbidity from malaria in African children. Trop Med Int Health. 2007;12:224-9.

36. Okoyo C, Mwandawiro C, Kihara J, Simiyu E, Gitonga CW, Noor AM, et al. Comparing insecticide-treated bed net use to Plasmodium falciparum infection among schoolchildren living near Lake Victoria. Kenya Malar J. 2015;14:515.

37. Gething PW, Casey DC, Weiss DJ, Bisanzio D, Bhatt S, Cameron E, et al. Mapping Plasmodium falciparum mortality in Africa between 1990 and 2015. N Engl J Med. 2016;375:2435-45.

38. Vanden Eng J, Thwing J, Wolkon A, Kulkarni MA, Manya A, Erskine M, et al. Assessing bed net use and non-use after long-lasting insecticidal net distribution: a simple framework to guide programmatic strategies. Malar J. 2010;9:133.

39. Msellemu D, Shemdoe A, Makungu C, Mlacha Y, Kannady K, Dongus S, et al. The underlying reasons for very high levels of bed net use, and higher malaria infection prevalence among bed net users than nonusers in the Tanzanian city of Dar es Salaam: a qualitative study. Malar J. 2017;16:423.

40. WHO. Guidelines for monitoring the durability of long-lasting insecticidal mosquito nets under operational conditions. Control of Neglected
Tropical Diseases; WHO Pesticide Evaluation Scheme and Global Malaria Programme Vector Control Unit. Geneva, World Health Organization, 2011. https://apps.who.int/iris/bitstream/handle/10665/44610/97892 41501705_eng.pdf? sequence $=1$. Accessed 6 Oct 2020

41. WHO. Achieving and maintaining universal coverage with long-lasting insecticidal nets for malaria control. Geneva, World Health Organization, 2017. https://apps.who.int/iris/bitstream/handle/10665/259478/WHOHTM-GMP-2017.20-eng.pdf;jessionid=8BA2B23DD9B4706F101A5A262 1121944 ? sequence $=1$. Accessed 30 Mar 2019

42. Balami AD, Said SM, Zulkefli NAM, Bachok N, Audu B. Effects of a health educational intervention on malaria knowledge, motivation, and behavioural skills: a randomized controlled trial. Malar J. 2019;18:41.

43. de Castro MC, Fisher MG. Is malaria illness among young children a cause or a consequence of low socioeconomic status? evidence from the united Republic of Tanzania. Malar J. 2012;11:161.

44. Kachur SP, Butler JRG, Njau J, Somi MF, Vahid F, Abdulla S. Is there evidence for dual causation between malaria and socioeconomic status? findings from rural Tanzania. Am J Trop Med Hyg. 2007;77:1020-7.

45. Ruberto I, Camara S, Banek K, Loua MK. Knowledge, attitudes and practices of malaria control among communities from the health district of Forécariah in the Republic of Guinea. West Africa J Vector Borne Dis. 2014;51:119-27.

\section{Publisher's Note}

Springer Nature remains neutral with regard to jurisdictional claims in published maps and institutional affiliations.
Ready to submit your research? Choose BMC and benefit from:

- fast, convenient online submission

- thorough peer review by experienced researchers in your field

- rapid publication on acceptance

- support for research data, including large and complex data types

- gold Open Access which fosters wider collaboration and increased citations

- maximum visibility for your research: over 100M website views per year

At BMC, research is always in progress.

Learn more biomedcentral.com/submissions 